Revista de

Estudios

Kantianos

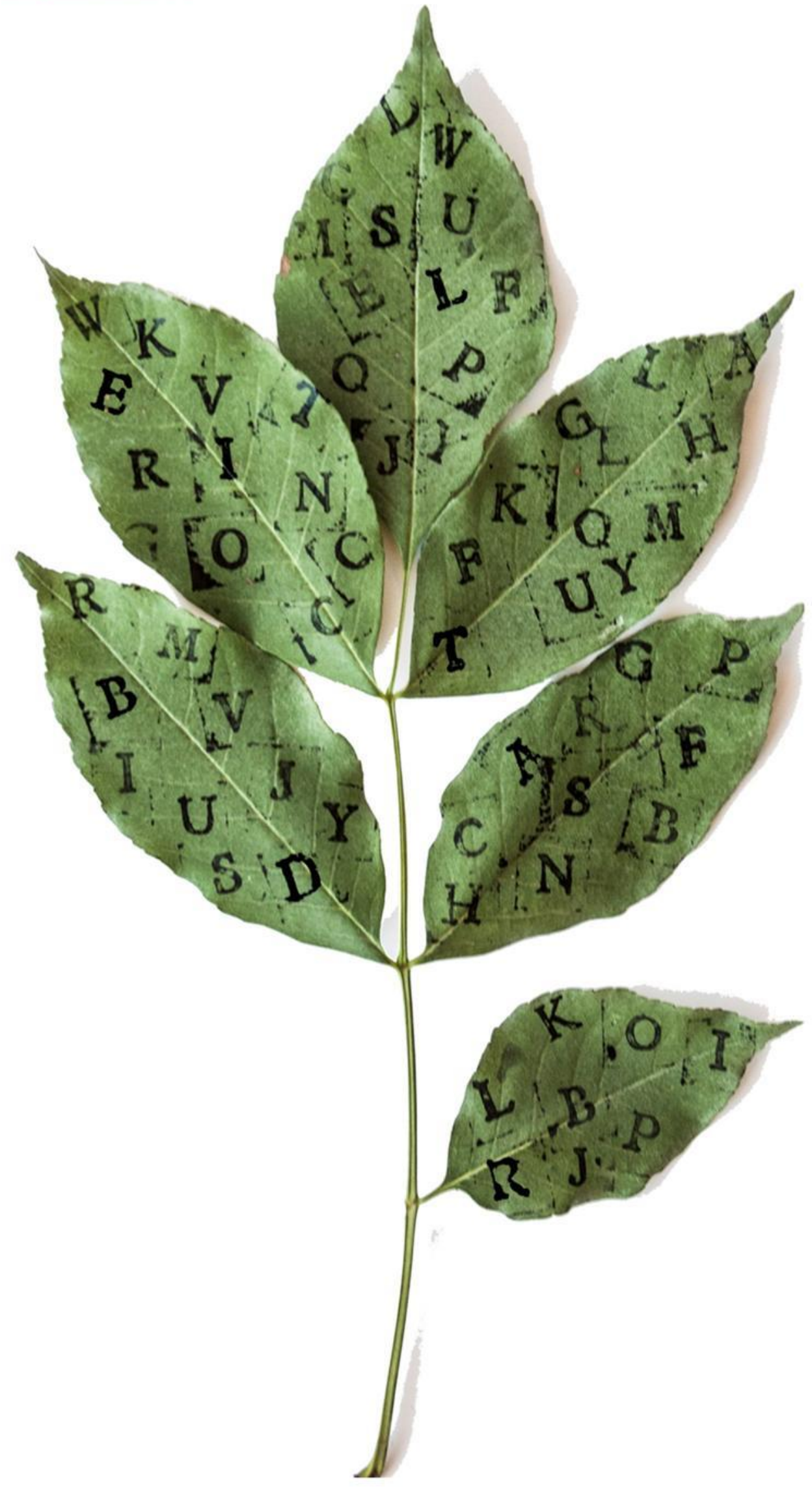




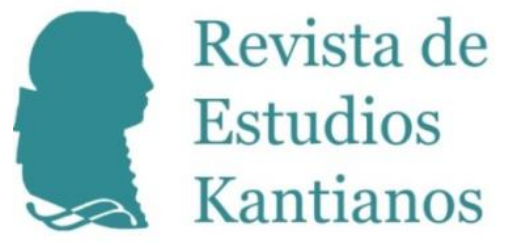




\title{
Revista de Estudios Kantianos
}

\author{
Publicación internacional de la Sociedad de Estudios Kantianos en Lengua Española \\ Internationale Zeitschrift der Gesellschaft für Kant-Studien in Spanischer Sprache \\ International Journal of the Society of Kantian Studies in the Spanish Language
}

\section{Dirección}

Fernando Moledo, FernUniversität in Hagen

fernando.moledo@fernuni-hagen.de

Hernán Pringe, CONICET-Universidad de Buenos Aires/

Universidad Diego Portales, Santiago de Chile

hpringe@gmail.com

\section{Secretario de edición}

Óscar Cubo Ugarte, Universitat de València

oscar.cubo@uv.es

\section{Secretaria de calidad}

Alba Jiménez Rodríguez, Universidad Complutense de Madrid

albjim04@ucm.es

\section{Editores científicos}

Jacinto Rivera de Rosales, UNED, Madrid

Claudia Jáuregui, Universidad de Buenos Aires

Vicente Durán, Pontificia Universidad Javeriana, Bogotá

Julio del Valle, Pontificia Universidad Católica del Perú, Lima

Jesús Conill, Universitat de València

Gustavo Leyva, Universidad Autónoma de México, México D. F.

María Xesús Vázquez Lobeiras, Universidade de Santiago de Compostela

Wilson Herrera, Universidad del Rosario, Bogotá

Pablo Oyarzun, Universidad de Chile, Santiago de Chile

Paula Órdenes Azúa, Universität Heidelberg 


\section{Comité científico}

Juan Arana, Universidad de Sevilla

Reinhardt Brandt, Philipps-Universität Marburg

Mario Caimi, Universidad de Buenos Aires

Monique Castillo, Université de Paris-Est

Adela Cortina, Universitat de València

Bernd Dörflinger, Universität Trier

Norbert Fischer, Universität Eichstätt-Ingolstadt

Miguel Giusti, Pontificia Universidad Católica del Perú

Dulce María Granja, Universidad Nacional Autónoma de México

Christian Hamm, Universidad Federal de Santa María, Brasil

Dietmar Heidemann, Université du Luxembourg

Otfried Höffe, Universität Tübingen

Claudio La Rocca, Università degli Studi di Genova

Juan Manuel Navarro Cordón, Universidad Complutense, Madrid

Carlos Pereda, Universidad Nacional Autónoma de México

Gustavo Pereira, Universidad de la República, Uruguay

Ubirajara Rancan de Azevedo, Universidade Estadual Paulista, Brasil

Margit Ruffing, Johannes Gutenberg-Universität Mainz

Gustavo Sarmiento, Universidad Simón Bolívar, Venezuela

Sergio Sevilla, Universitat de València

Roberto Torretti, Universidad Diego Portales, Santiago de Chile

Violetta Waibel, Universität Wien

Howard Williams, University of Aberystwyth

Allen W. Wood, Indiana University

Diseño, revisión de estilo, corrector y maqueta

Josefa Ros Velasco, Harvard University, Cambridge (MA)

\section{Entidades colaboradoras}

Sociedad de Estudios Kantianos en Lengua Española (SEKLE)

Departament de Filosofia de la Universitat de València

Instituto de Humanidades, Universidad Diego Portales

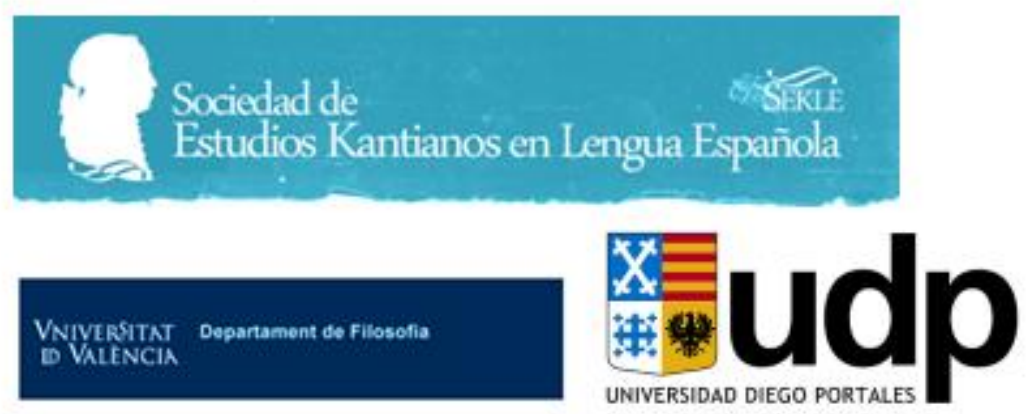




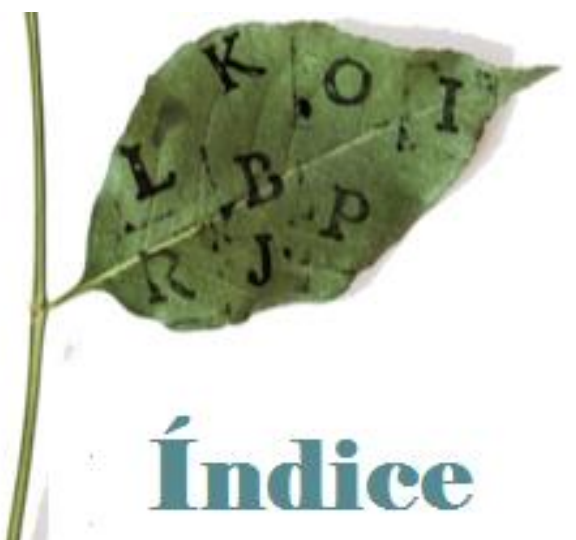

\section{Artículos}

1 El concepto teórico de libertad según Kant y la tradición de la libertas spontaneitatis

Thomas Sören Hoffmann

DOI 10.7203/REK.4.1.14849

21 From the unity of sensible intuition to the sensible unity of intuition. Revisiting the proof-structure of Kant's B-Deduction argument Adriano Perin

DOI: 10.7203/REK.4.1.12644

44 The Principle of the Transcendental Deduction. The First Section of the Deduction of the Pure Concepts of the Understanding

Rudolf Meer

DOI: 10.7203/REK.4.1.14339

63 ¿Por qué son — según Kant — imposibles las hipótesis en matemática?

Reyna Fortes

DOI: 10.7203/REK.4.1.12777 
90 El reino de los fines y la comunidad ética. Acerca de la dimensión intersubjetiva de la ética kantiana

Ileana Beade

DOI: 10.7203/REK.4.1.12775

\section{Recensiones}

113 Mario Caimi: Kant's B Deduction. Newcastle upon Tyne, Cambridge Scholars Publishing, 2014, 140 pp. ISBN (13): 978-1-4438-6537-1 Paola Rumore

DOI: 10.7203/REK.4.1.14280

121 Gustavo Leyva, Álvaro Peláez y Pedro Stepanenko (Eds.): Los rostros de la razón: Immanuel Kant desde Hispanoamérica (3 volúmenes). México, UAM-Cuajimalpa/Anthropos, 2018, 727 pp. ISBN (UAM): 978-607-28-1348-9/ISBN (Anthropos): 978-8416421-91-6

Francisco Javier Iracheta Fernández.

DOI: 10.7203/REK.4.1.14135

134 Ileana Beade: La libertad y el orden en la filosofía jurídica kantiana. Rosario, Fhumyar Ediciones, 2017, 310 pp. ISBN: 978-987-3638-169

Marilín Gómez.

DOI: $10.7203 /$ REK.4.1.14266

138 Christian Krijnen (Ed.): Metaphysics of Freedom? Kant's Concept of Cosmological Freedom in Historical and Systematic Perspective.

Leiden/Boston, Brill (Critical Studies in German Idealism, vol. 23), 2018, 221 pp. ISBN: 978-90-40-38377-7

Jacinto Páez.

DOI: 10.7203/REK.4.1.14337 


\section{Traducción}

145 Salomon Maimon frente a la filosofía trascendental. Traducción de algunas cartas sobre su filosofía teórica

David Hereza Modrego

DOI: 10.7203/REK.4.1.13956

\section{Informes}

173 Informe del IV Congreso Internacional de la SEKLE Alejandra Baher

Luciana Martínez

DOI: 10.7203/REK.4.1.14281

178 Ata do Simpósio Internacional de Kant a Hegel Agemir Bavaresco

Jair Tauchen

Evandro Pontel

DOI: 10.7203/REK.4.1.14269

\section{Eventos y normas para autores}

185 Normas para autores 


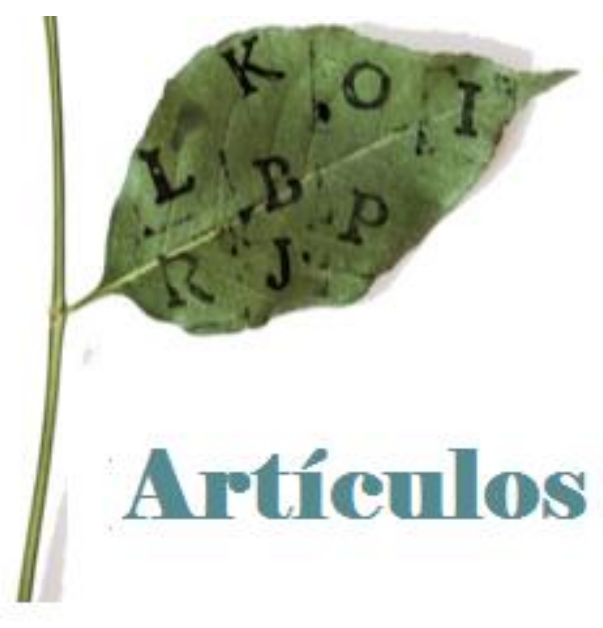




\title{
From the unity of sensible intuition to the sensible unity of intuition: revisiting the proof-structure of Kant's B- Deduction argument
}

\author{
ADRIANO PERIN ${ }^{1}$
}

\begin{abstract}
The B-Deduction accounts for Kant's utmost solution at safeguarding both the distinctiveness and a necessary relation between understanding and sensibility. I aim at proposing an original thesis to the debate on this solution: the B-Deduction argument profits from a methodology correlating the unity of sensible intuition to the sensible unity of intuition. At first, Kant's definition of "transcendental cognition" is set forth. Secondly, an inquiry into the argument's methodology is carried out. After that, the justification of the categories within the understanding's domain is taken into account. Finally, the relation of the understanding to sensibility is brought into discussion.
\end{abstract}

Keywords: deduction, understanding, sensibility, categories, unity of intuition

De la unidad de la intuición sensible a la unidad sensible de la intuición: revisitando la estructura de prueba del argumento kantiano de la Deducción-B

\begin{abstract}
Resumen
La Deducción-B representa la última solución de Kant tanto para la preservación de la diferenciación entre entendimiento y sensibilidad como para el establecimiento de una relación necesaria entre esas facultades. Mi objetivo es proponer una tesis original al debate sobre esta solución: el argumento de la Deducción-B se beneficia de una metodología que correlaciona la unidad de la intuición sensible a la unidad sensible de la intuición. Primeramente, presento la definición kantiana de "conocimiento trascendental". Enseguida, investigo la metodología del argumento. Después, considero la justificación de las categorías en el dominio propio del entendimiento. Por fin, discuto la relación del entendimiento a la sensibilidad.
\end{abstract}

Palabras clave: deducción, entendimiento, sensibilidad, categorías, unidad de la intuición

\footnotetext{
${ }^{1}$ Câmpus Criciúma do Instituto Federal de Santa Catarina (IFSC).
}

Contact: adriano.perin@ ifsc.edu.br. 
1. An overview of the problem

Kant finds in the term 'transcendental' the expression of the singularity of his philosophy. This is due to the fact that this philosophy attends to a particular kind of cognition, i.e., that which aims at grounding what is empirical without counting on anything transcendent.

At first glance, it might appear that, represented in such a description, the definition of cognition is invariably accurate. Yet, one must not forget that, in the two editions of the Critique of pure reason, Kant gives two different definitions of 'transcendental cognition'.

In the 1781 edition, Kant states: "I call transcendental all cognition that is, in general, occupied not so much with objects but rather with our $a$ priori concepts of objects" ( $K r V$ A11, a. trans. $)^{2}$ In the 1787 edition, he states "I call transcendental all cognition that is, in general, occupied not so much with objects but rather with our manner of cognition of objects insofar as this is to be possible a priori" ( $K r V \mathrm{~B} 25$, a. trans.).

A thorough discussion of this difference requires addressing the following questions: i) What is the meaning of Kant's change in the seminal label of his philosophy? ii) Why Kant no more took the task of his philosophy to be restricted to mere 'concepts' and presented it as endorsing 'our manner of cognition of objects'? iii) What was missing in the former approach, so that Kant saw the necessity of presenting a second definition?

It has been noted in the secondary literature that, with the change in the definition of 'transcendental cognition', Kant aimed at including in it his argumentation either in the Aesthetic (Erdmann 1900: 28), or in the Dialectic (Hinske 1970: 39), or even still in the Doctrine of Method (Baumanns 1997: 93).

\footnotetext{
2 The German text here reads: "Ich nenne alle Erkenntniß transcendental, die sich nicht sowohl mit Gegenständen, sondern mit unsern Begriffen a priori von Gegenständen überhaupt beschäftig”. In the way in which '"̈̈berhaupt' is placed in this sentence, it can be understood either as an adjective (therefore, related to 'Gegenständen') or as an adverb (therefore, related to 'beschäftig'). In the passage from the second edition, which is presented in the following, Kant makes it clear that 'überhaupt' is presented as an adverb: "Ich nenne alle Erkenntniß transscendental, die sich nicht sowohl mit Gegenständen, sondern mit unserer Erkenntnißart von Gegenständen, so fern diese a priori möglich sein soll, überhaupt beschäftigt" ( $K r V \mathrm{~B} 25)$. In quoting the Critique of pure reason, I use the standard reference to $\mathrm{A}$ and $\mathrm{B}$, indicating the first and second edition respectively. I generally follow Paul Guyer's translation mentioned in the References section. Whenever I do not, I indicate it in the corresponding footnote. All other Kant's texts are referenced in the Akademie Ausgabe (AA), with volume and page. In all quotations, emphasis is my own.
} 
In this essay, I argue that the change in the definition of 'transcendental cognition' is due to Kant's approach of the task of the deduction of the categories in the B-Deduction argument. So, I maintain that, in the change provided in the 1787 Introduction, Kant is assuring that, in the B-Deduction, he had finally accounted for the relation of the faculties of sensibility and understanding and, therefore, for 'our manner of cognition of objects'.

The thesis advanced is that this account relies on a methodology that presents the categories as concepts grounding the unity of sensible intuition and then leads into their justification as presiding over the sensible unity of intuition.

This thesis is supported, in the following sections of the paper, in three moments: the next section discusses the method followed in the B-Deduction argument; the third section deals with the justification of the categories within the domain of the faculty of the understanding; the fourth and final section delves into the task of relating the understanding to sensibility.

2. On the method of argumentation followed in the B-Deduction argument

In a passage from the Introduction to the second edition of the Critique, Kant points out that the analytic method is not sufficient for taking into account the task of philosophy:

$[\ldots]$ the mere analysis of the concepts that inhabit our reason a priori, is not the end at all, but only a preparation for metaphysics proper, namely extending its a priori cognition synthetically, and it is useless for this end, because it merely shows what is contained in these concepts, but not how we attain such concepts a priori in order thereafter to be able to determine their valid use in regard to the objects of all cognition in general ( $K r V$ A13-14/B23-24).

Making sense of Kant's claim that analysis of concepts 'is not the end' [Zweck] in philosophy and, moreover, is useless [untauglich] for this end, requires that we catch on what he means by 'end'. By 'end', in this claim, Kant means a fundamental condition of justification in which a procedure peculiar to philosophy is carried out. Since such a procedure in philosophy implies 'extending its a priori cognition synthetically', it must be a synthetic 
one, ensuring, conjointly and necessarily, that concepts are attained a priori and have a valid use.

By focusing on the B-Deduction argument, one can say that what Kant is holding is that a method which provides "the mere analysis of the concepts that inhabit our reason a priori" and, with this, "shows what is contained in these concepts" is not appropriate for ensuring both the validity of pure concepts within the domain of the understanding and likewise their legitimate use in the domain of sensibility. As Kant puts it: "[...] this analysis would not be purposeful [zweckmäßig], since it does not contain the difficulty encountered in the synthesis on account of which the whole Critique is actually undertaken" (KrV B27-28).

Given this, one must also consider that Kant does not dismiss the analytic means which, as backward or preparatory procedures, conduct his argumentation to that fundamental condition of justification defined as the 'end'. As he points it out: "[a] great part, perhaps the greatest part, of the business of our reason consists in analyses of the concepts that we already have of objects" ( $K r V$ A5/B8). Yet, with regard to the ground of this great(est) business, Kant immediately ensures, in the following, that "[...] reason adds something entirely alien to given concepts and indeed does so a priori" $(\mathrm{KrV}$ A6/B10).

On the basis of the account that the analytic method is a way back to a justification which can only be given by a synthetic method, one can also grasp what Kant was getting at in this warning: "[...] we need to take the analysis only as far as is indispensably necessary in order to provide insight into the principles of a priori synthesis in their entire scope, which is our only concern" (KrV A12/B25).

In light of these considerations given in the B-Introduction-namely, the conception of analysis as insufficient but as a necessary first procedure for the approach of the task of the deduction-one can find a methodological hint to the structure of Kant's B-Deduction argument.

Kant structures the B-Deduction in such a way that, in its first part, it contends with an 'indispensably necessary' analysis of the domain of the faculty of the understanding; so as to ensure, in its second part, that the synthesis would also provide its relation to the domain of sensibility. While the former is preparatory and indispensable, the latter is 'purposeful' for 
holding the task on behalf of which the 'whole Critique is actually undertaken'.

Underlying this methodology lies the recognition that the focus of analysis is no more the total amount of human cognition-which, in the ADeduction, had been presented as a subjective consideration of the faculties supposedly grounding this cognition and, in the Prolegomena, as its 'depuration' out of the domain of sensible perception (see $K r V$ AXVI-XVII, A97; Prol, AA 04: 297-298). Now, the goal of the analysis is what is pure spontaneity, i.e., the domain of the pure understanding.

This is due to the fact that, in the B-Deduction argument, Kant sees that an analytical procedure is to be advanced only to the extent that the domain of the faculty of the understanding is primarily investigated; so as to ensure that this faculty is the ground of determination of what, by means of its relation to the domain of sensibility, must be justified as a priori cognition. This relation, however, would only be presented by a synthetic method of investigation.

In the following two sections, a consideration of how Kant structures the B-Deduction argument according to these two procedures may give us a key to determining how the task of the deduction is actually fulfilled in this argument.

3. The unity of sensible intuition: rendering the justification of pure concepts without any help from the domain of sensibility

Before undertaking the arduous task of facing Kant's dense argumentation within $§ 15-\S 20$ of the B-Deduction, it is helpful to briefly consider that the introductory section of the Transcendental Logic, presented in the 1781 edition and maintained in the 1787 edition, offers the ground upon which a deduction of the categories had to be advanced. In a word, we must initially take into account Kant's insight into the need for a first-step argument attending exclusively to the domain of the faculty of the understanding.

As the starting point, Kant sets the peculiarity of the faculty of the understanding: 
[t]he pure understanding separates itself completely not only from everything empirical, but even from all sensibility. It is therefore a unity that subsists on its own, which is sufficient by itself, and which is not to be supplemented by any external additions ( $\mathrm{KrV}$ A65/B89-90).

In the context of this characterization, one reads the nature of a consideration of understanding within its own domain: "[...] we isolate the understanding $[\ldots]$ and elevate from our cognition merely the part of our thought that has its origin solely in the understanding" ( $K r V$ A62/B87).

Since, in this consideration, it is not given that element which, "[ $[.$. to us [humans]", "[...] takes place only insofar as the object is given to us" ( $K r V$ A19/B33) - i.e., intuition in the domain of sensibility-; what remains is merely " $[\ldots]$ the expectation $[\ldots]$ that there can perhaps be concepts that may be related to objects a priori, not as pure or sensible intuitions but rather merely as acts of pure thinking" $(K r V$ A57/B81).

On the basis of this specific situation that is presented in the justification of the categories, Kant ponders that the above-cited 'expectation' could only be ferreted out by means of an 'analytic of concepts'.

Nevertheless, Kant is convinced that, in such a procedure, he can neither follow the tradition nor his own account in the 1760s on behalf of an analysis that, while rendering concepts clear(er), would be the only method to be followed in philosophy. ${ }^{3}$ As he puts it:

I understand by an analytic of concepts not their analysis, or the usual procedure of philosophical investigations, that of analyzing the content of concepts that present themselves and bringing them to distinctness, but rather the much less frequently

\footnotetext{
${ }^{3}$ Here is a point of disagreement with Caimi (2014: 11-12). Caimi argues that "[i]f we observe the argumentative course Kant takes in the Critique of Pure Reason, and especially in the development of the Transcendental Deduction, we find that it closely coincides with the description of the method of philosophy he had expounded in some of his 1762-1763 writings. Whoever proceeds according to this method receives a concept which is initially confused and whose origin is undetermined, and engages in the task of bringing distinction to it". In his reading of this disagreement, Caimi pointed out that he is not asserting that the method of analysis is sufficient for carrying out the task of the Critique, but emphasizing, as I do, that there is a moment of analysis in its argumentative path. Nevertheless, I would like to express my disagreement in the sense that my position seems to be more radical regarding Kant's pre-critical and critical approaches to the method of philosophy. I do believe that in 1760 Kant took analysis to be the single method of philosophy, while the critical Kant took it to be just a way to the development of synthesis, which is now seen as the moment in charge of presenting the ground of any philosophical investigation.
} 
attempted decomposition of the faculty of understanding itself [Zergliederung des Verstandesvermögens selbst], in order to research the possibility of a priori concepts by seeking them only in the understanding as their birthplace $(\mathrm{KrV}$ A65/B90, a. trans.).

Two points of this passage are of particular interest in what matters to the critical importance of the method of analysis. One is Kant's rupture with the previous accounts on the adoption of analysis of the content of cognition and concepts as the unique procedure to be followed in philosophy. In a word, in his critical approach, Kant sees the analytical method not as related to the total amount of human cognition, but solely to one of the faculties grounding this cognition. That is to say, analysis is important to determine or decompose each of the domains of human cognition, i.e., the intuitive domain of sensibility and the discursive domain of the understanding.

In another passage, Kant gives the reason for this restriction in the use of the analytic method:

[...] synthesis alone is that which properly collects the elements for cognitions and unifies them into a certain content; it is therefore the first thing to which we have to attend if we wish to judge about the first origin of our cognition ( $K r V$ A77-78/B103).

This is due to the fact that, in what regards the total amount of our cognition, "[p]rior to all analysis of our representations these must first be given, and no concepts can arise analytically as far as the content is concerned" (KrV A77/B103).

The second point of interest is Kant's adoption of the analytic method in the first part of the B-Deduction argument. In leading away from the application of the analytic method to human cognition in its entirety and moving over to its use so as decompose the faculty of the understanding in its own domain, Kant establishes the way to fulfill the task of the deduction. This means that, in its methodology, the B-Deduction starts with the distinctiveness of the faculties of sensibility and understanding and sets the latter as the one in charge of determining what is giving in the former.

Kant notes that the domain of sensibility had been autonomously justified in the Transcendental Aesthetic, i.e., it alone "[...] traced the 
concepts of space and time to their sources [...] and explained and determined their a priori objective validity" (KrV A87/B119-120). Now, regarding the domain of the understanding, it remains as unsettled the justification that pure concepts "[...] speak of objects not through predicates of intuition and sensibility but through those of pure a priori thinking", i.e., that "[...] they relate to objects generally without any conditions of sensibility" ( $\mathrm{KrV}$ A88/B120).

On this pending matter, Kant states that " $[\mathrm{t}]$ ranscendental philosophy has the advantage but also the obligation to seek its concepts in accordance with a principle, since they spring pure and unmixed from the understanding, as absolute unity" ( $\mathrm{KrV}$ A67/B92).

It is worth taking into account that Kant's use of 'pure' [rein] and 'unmixed' [unvermischt] — which, in other contexts, would be synonyms -is due to the particular context of transcendental philosophy in its justification of the categories as non-empirical (pure) and different from that which belongs to domain of sensibility (unmixed). ${ }^{4}$ Such a justification, in the clue given in the above-cited passage, must start with the consideration of the understanding as 'absolute unity'.

Let us consider how Kant presents, within the B-Deduction argument, the discursivity of human understanding as pure, unmixed and grounded upon the unity of the act of representation.

In $\S 16$, Kant presents the self's act of thinking as an activity belonging solely to the faculty of understanding. According to him, its representation consists of the following attributes: i) "spontaneity": "[...] it cannot be

\footnotetext{
${ }^{4}$ Kant presents, at the beginning of the B-Deduction argument, a defense of the non-empirical (pure) way in which the categories are originated. Accordingly, in the fragment added to $\$ 14$ in the second edition, he provides a brief but precise criticism to what he calls 'empirical derivation' of the categories in the attempts advanced by Locke and Hume. As to Locke, Kant states that "[...] because he encountered pure concepts of the understanding in experience, [he] also derived them from this experience, and thus proceeded so inconsistently that he thereby dared to make attempts at cognitions that go far beyond the boundary of all experience" ( $K r V$ B127). With regard to Hume, Kant maintains that he "[...] derived them from experience (namely from a subjective necessity arisen from frequent association in experience, which is subsequently falsely held to be objective, i.e., custom); however he subsequently proceeded quite consistently in declaring it to be impossible to go beyond the boundary of experience with these concepts and the principles that they occasion" (KrV B129). According to Kant, the results of these enterprises are, respectively, fanaticism [Schwärmerei] and skepticism [Skeptizismus]. A deduction of the pure concepts of the understanding is, therefore, "[...] an attempt to see whether we cannot successfully steer human reason between these two cliffs, assign its determinate boundaries, and still keep open the entire field of its purposive activity" ( $K r V$ B129). Once one has done this, that unmixed way in which the categories 'spring' from the understanding would also be ferreted out.
} 
regarded as belonging to sensibility"; ii) "pure apperception": "[...] in order to distinguish it from the empirical one"; iii) "original apperception": "[...] it is that self-consciousness which, because it produces the representation $I$ think, which must be able to accompany all others and which in all consciousness is one and the same, cannot be accompanied by any further representation" ( $K r V$ B132).

In addition to the two attributes already considered-i.e., its pure and unmixed character-, now the faculty of the understanding is presented as an act of thinking which is an original apperception. With this characterization, Kant means that the act of thinking is free from all determinations as well as from external and object relations. It represents, therefore, the unity, the identity and the absolute independence of the self from any other representation. Kant states that this 'other representation' could be either an intuition or a concept.

With this characterization of the understanding as original apperception, Kant aims at establishing it as a faculty of thinking that, on behalf of human cognition, grounds its own domain and the domain of the faculty of sensibility. In Kant's words, this unity of thinking accounts for "[...] the transcendental unity of self-consciousness in order to designate the possibility of a priori cognition from it" (KrVB132).

Thus, the B-Deduction argument begins with a pre-epistemological approach of the faculty of understanding in order to ensure, within the sphere of human cognition, both the distinctiveness of sensibility and understanding and the determination of the former by the latter.

Kant ensures that, in order to handle this task, one must start by attending to the following propositions:

i) The I think must be able to accompany all my representations.

ii) For otherwise something would be represented in me that could not be thought at all, which is as much as to say that the representation would be nothing for me (from i)).

iii) That representation that can be given prior to all thinking is called intuition iv) Thus all manifold of intuition has a necessary relation to the I think in the same subject in which this manifold is to be encountered (from ii) and iii)) ( $\mathrm{KrV}$ B131-132). 
The modalization offered in propositions i) and iii)—i.e., "must be able" and "can be given" - aims precisely at safeguarding the self-sufficiency of understanding and sensibility. Thus, regarding what is thought and what is sensibly given, no foundation in terms of origin or derivation is carried out. ${ }^{5}$

Therefore, Kant's equivalent statements that the I think may not accompany a representation of the self and that intuition, as a representation of the self, may be given before an act of thinking, only and precisely mean that this representation alone would be nothing for the self with regard to cognition. ${ }^{6}$

Proposition iv) could be taken as a confirmation that, already in $\S 16$, Kant is ensuring a necessary relation between sensibility and understanding. Nevertheless, one cannot forget that this proposition relies upon two modalized propositions. Accordingly, looking for this necessary relation in proposition iv) would imply that at least one of the modalizations in propositions i) and iii) is called off. That is to say, in order to grasp that what is sensibly given is related to what belongs to an act of thinking, one would have to assume that the self's act of thinking is, in fact, accompanying everything that is sensibly given or, correlatively, that everything that is sensibly given is originated in this act of thinking.

Here, it is enough to say that Kant's central thesis of an original distinctiveness between the two stems of human cognition dismisses both these possibilities. Thus, the proposition "all manifold of intuition has a necessary relation to the I think in the same subject in which this manifold is to be encountered" only means that, if a manifold of representations is given to this subject, then it is accompanied by an act of thinking which provides consciousness of the unity of its representations.

In this proposition, Kant is not handling further the discussions on that and how a manifold of representations is given to the subject. In a word, Kant's goal is to justify a necessary relation between the unity of a possible

\footnotetext{
${ }^{5}$ It is worth taking into account that this modalization, in the description of the spontaneity of thought as well as of the receptivity of sensibility, grants that what is at stake in the first part of the B-Deduction argument is not a manifold already united in its representations. Accordingly, here is a point of disagreement with Henrich in what regards his well-known thesis that, up to §20, Kant "[...] established that intuitions are subject to the categories insofar as they, as intuitions, already possess unity" (Henrich 1969: 645).

${ }^{6}$ Allison overlooks this feature of Kant's argumentation in his commentary that " $[\ldots]$ it is somewhat surprising that Kant begins the section [\$16] with a reflection on the conditions of the possibility of intuition" (2015: 349).
} 
manifold of representations and the unity of consciousness of the subject: "[...] the manifold representations that are given in a certain intuition would not all together be my representations if they did not all together belong to a self-consciousness" $\left(K r V\right.$ B132) ${ }^{7}$

Now, considering that and how a manifold of representation is given as united respectively accounts for an epistemological justification of the understanding in itself as well as in its relation to sensibility.

Kant's account that a manifold of representations is given as united by the faculty of the understanding is an important and challenging moment of his argumentation. The crucial point here is the demonstration that the understanding, which is as a faculty of thinking, can actually provide, in its own domain, the synthesis of what is given as manifold in every representation presiding over cognition. ${ }^{8}$ Therefore, in this first account, what is amenable to proof is that any manifold of representations that is given to the subject as objectively united rely on pure concepts of the understanding.

In approaching this first account, one must follow what Kant now presents as an "explanation of the categories": "[ $\mathrm{t}]$ hey are concepts of an object in general, by means of which its intuition is regarded as determined with regard to one of the logical functions for judgments" (KrV B128). In this explanation [Erklärung], Kant is emphasizing that the categories ensure the determination of intuition's manifold (i.e., any manifold of representations given to the subject on behalf of cognition) as necessarily grounded upon the

\footnotetext{
${ }^{7}$ It is worthwhile mentioning that, in working towards this goal, Kant is taken on the results of $\S 15$. In it, Kant considers "[...] the possibility of a combination in general" and advances a regressive argumentation asserting that i) "[t]he manifold of representations [, which] can be given in an intuition that is merely sensible, i.e., nothing but receptivity" implies (ii.) the understanding activity of synthesis, this due to the fact that combination "[...] is an act of the spontaneity of the power of representation" and that iii) the understanding activity of synthesis-i.e., "[...] the combination (conjunctio) of a manifold in general"-_....] carries with it the concept of the unity of the manifold". Kant states that the unity of the manifold is provided neither by the receptivity of sensibility nor by the understating activity of synthesis (combination). Thus, it is necessary to "[...] seek this unity [...] someplace higher, namely in that which itself contains the ground of the unity of different concepts in judgments, and hence of the possibility of the understanding, even in its logical use". In short, Kant is emphasizing that the unity of a manifold of representation - being the latter sensibly given and the former implied in the understanding's activity of synthesis - could only be so on account of the subject's consciousness own unity. It is this original unity of the self-i.e., original apperception - that, from $\$ 16$ on, will be justified as the original condition of possibility of the categorical synthesis of the sensible manifold (all fragments in $K r V$ B129-131).

${ }^{8}$ Accordingly, the first part of the B-Deduction argument ( $\left.\$ 15-\S 20\right)$ aims precisely at justifying a wellknown claim from $\S 10$ : "[t]he same function that gives unity to the different representations in $a$ judgment also gives unity to the mere synthesis of different representations in an intuition" ( $\mathrm{KrV}$ A79/B104-105).
} 
unity of representations that is given by the understanding as a faculty of thinking or judging.

The account that a manifold of representations in a given intuition is necessarily subjected to the categories is provided by Kant in $§ 15-\S 20$ of the B-Deduction argument. In this part of the B-Deduction, Kant develops an analytical-regressive analysis of the domain of the faculty of the understanding.

In order to grasp what Kant was getting at in this part of the argument, it is essential that one attends to his outline provided in $\S 20$ :

i) The unity of a given intuition in general, as a necessary outcome of the understanding's activity of synthesis, is only possible due to apperception's original synthesis. Therefore, any sensible intuition given to the subject is necessarily under the unity of apperception $(\S 15-\S 17) ;{ }^{9}$

ii) "The transcendental unity of apperception is that unity through which all of the manifold given in an intuition is united in a concept of the object" $(K r V \mathrm{~B} 139, \S 18)$;

iii) The necessary subordination of a manifold of representations to the apperception amounts to the logical function of judgments. For " $[\ldots]$ a judgment is nothing other than the way to bring given cognitions to the objective unity of apperception" $(K r V \mathrm{~B} 141, \S 19) ;{ }^{10}$

\footnotetext{
${ }^{9}$ It is worth taking into account that, in the first part of the B-Deduction argument, Kant takes the expression 'sensible intuition' merely as a manifold of representations that is given to and not by the faculty of the understanding. As he puts it: "[t]he pure concepts of the understanding are related through the mere understanding to objects of intuition in general, without it being determined whether this intuition is our own or some other but still sensible one" $(\mathrm{KrV} \mathrm{B} 150)$.

${ }^{10}$ One can find, within Kant's corpus, other definitions of 'judgment' similar to this one that is given in the B-Deduction:

i) "The unification of representations in a consciousness is judgment" (Prol, AA 04: 304).

ii) "A judgment is the representation of the unity of the consciousness of various representations, or the representation of their relation insofar as they constitute a concept" ( $V$ - $\log$, AA 09: 156).

iii) "A judgment is the representation of the way that concepts belong to one consciousness universally [and] objectively" ( $V$ - $\log$, AA 24: 928).

iv) "The representation of the way in which different concepts (as such)* belong to one consciousness** (in general (not merely mine)) is the judgment. They belong to one consciousness partly in accordance with laws of the imagination, thus subjectively, or of the understanding, i.e., objectively valid for every being that has understanding. The subjective connection pertains to the particular situation of the subject in experience. * (universally necessary (empirical or a priori)) ** (Later addition: Concepts belong to one consciousness only insofar as they are conceived under one another, not next to one another (like sensations).)" (Refl 3051, AA 16: 633, quoted in Longuenesse 2000: 88-89).
} 
iv) Categories are correlated to the logical functions of judgment. This is due to the fact that, within the domain of the understanding, the former "[...] are only rules for an understanding whose entire capacity consists in thinking, i.e., in the action of bringing the synthesis of the manifold that is given to it in intuition from elsewhere to the unity of apperception" ( $\mathrm{KrV}$ B145, §20); ${ }^{11}$

v) "All sensible intuitions stand under the categories, as conditions under which alone their manifold can come together in one consciousness" (Thesis of the first part of the B-Deduction) $(K r V \mathrm{~B} 143) .{ }^{12}$

We are now in a position to summarize Kant's argumentation within $\S 15-\S 20$ of the B-Deduction. Kant's first relevant assertion is that categories, in their activity of synthesis, necessarily call upon a given manifold of representations (a sensible intuition in general) and the unity of consciousness. His second noteworthy assertion is that the correlation of categories with the logical functions of judgment presides over a necessary and objective determination of that manifold by the unity of consciousness so that it can become cognition to the subject.

In taking root of the B-Deduction argument with an analytical approach of the understanding's own domain, Kant provides three important results: i) the self-sufficiency of the sensible and intellectual domains of human cognition is preserved; ii) the understanding's characterization as an active and determining faculty is ensured; iii) the possibility of accomplishing the task of the deduction, by means of a demonstration of the necessary relation between the understanding and sensibility, is raised. Let us take into account, in the following section, this last result.

4. The sensible unity of intuition: rendering the relation of the understanding to sensibility

Two features of the first part of the B-Deduction argument allow Kant to cope with the relation of sensibility and understanding in its second part. One is the establishment of the unity of consciousness as the principle upon which any representation aiming at cognition (whether an intuition or a concept) must

\footnotetext{
${ }^{11}$ Although this passage is from $\S 21$, it explains Kant's account in $\S 20$ that "[...] the categories are nothing other than these very functions for judging" ( $K r V$ B143).

12 This sentence is the heading of $\$ 20$.
} 
rely. It is worthwhile mentioning that this feature is set as a preepistemological one but as a necessary epistemological presupposition. The other feature is the account that, from the unity of consciousness, it is possible to justify the unity of a given manifold of representations (an intuition in general) without yet counting on sensibility. ${ }^{13}$

Accordingly, in the second part of the B-Deduction, Kant takes on the premises that any unity of representations implies the unity of consciousness and that the former (as intuition) is necessarily synthesized by categories according to the latter, in order to become cognition. Now, rendering the relation of understanding and sensibility requires showing that this activity of synthesis is operative within the domain of human intuition.

In the Anmerkung provided in $\$ 21$, Kant emphasizes that the achievement of the task of the deduction requires demonstrating the relation at issue. According to him, in the assertion that follows from the two abovementioned premises of the first part of the argument, i.e., "[a] manifold that is contained in an intuition that I call mine is represented as belonging to the necessary unity of self-consciousness through the synthesis of the understanding, and this takes place by means of the category", only "[ $\ldots]$ the beginning of a deduction of the pure concepts of the understanding has been made, $[. .$.$] since the categories arise independently from sensibility merely in$ the understanding" ( $K r V \mathrm{~B} 144)$. What is still lacking is "[...] the explanation of the a priori validity of the categories in regard to all objects of our senses" (KrV B145). With this, Kant claims, "[...] the aim of the deduction will first be fully attained" $(K r V \mathrm{~B} 145)$.

In attending to the domain of human sensibility in the second part of the B-Deduction, Kant characterizes the argument as an epistemological justification of the relation of this faculty with the understanding. As he states: "[...] for us, thinking of an object in general through a pure concept of the understanding can become cognition only insofar as this concept is related to objects of the senses" ( $K r V$ B146).

Moreover, he observes that "for us" human beings, "[s]ensible intuition is either pure intuition (space and time) or empirical intuition of that

\footnotetext{
${ }^{13}$ Kant points out these two features in a letter to Beck from 1792: "I wanted to present the categories themselves as concepts that make it possible to think of objects in general (be the intuition of whatever form it will), and then I wanted also to determine their extension beyond the boundaries of sense, an extension which however yields no cognition" (Br, AA 11:314).
} 
which, through sensation, is immediately represented as real in space and time" ( $K r V$ B146-147). In brief, the consideration of how a manifold of representations is given is at issue. These two ways in which human sensibility is presented are now the elements to be considered in the demonstration of how all human sensible intuition is necessarily determined by the categories.

In $\S 24$, Kant explains how pure intuitions of human sensibility are determined by the categories. In order to do so, he advances a consideration of space and time as pure forms of intuition. Kant credits this step of his argumentation, within the second part of the B-Deduction, to the transcendental synthesis of imagination, which he names synthesis speciosa.

Kant aims at justifying that this synthesis accounts for the transcendental determination of space and time as pure forms of intuition and that this synthesis is correlated to the a priori synthesis performed by the categories, i.e., synthesis intellectualis.

Kant begins by pointing out that, with regard to "[...] the ground of the possibility of cognition a priori", "[...] in us [human beings] a certain form lies at the ground of sensible intuition a priori, a form that rests on the receptivity of the capacity for representation (sensibility)" ( $K r V$ B150, a. trans) and presents the "[...] unity of the apperception of the manifold of sensible intuition, the condition under which all objects of our (human) intuition must necessarily stand" ( $K r V \mathrm{~B} 150)$.

This passage presents the relation of what belongs essentially to the understanding, i.e., the discursivity of thought or apperception with that which belongs solely to sensibility, i.e., the giveness under the forms of space and time.

Before proceeding to an explanation of this assertion, one must keep in mind that it holds two dismissed efforts: neither an analysis of the understanding would explain the way in which objects are given to human beings nor an analysis of sensibility would provide the unity of the manifold of representations in it. Accordingly, a method that presents the synthetic $a$ priori relation of spontaneity and receptivity is in need. In $\S 24$, Kant presents the imagination and its activity of synthesis as the element in charge of such a task. 
Kant's most prominent definition of imagination in the B-Deduction is this: "[...] IMAGINATION is the faculty for representing an object even without its presence in intuition" ( $K r V$ B151). In bearing in mind that representations can be given either as intuitions or as concepts, one will notice Kant's hybrid characterization of imagination is this definition. As he puts it:

[...] since all of our intuition is sensible, the imagination, on account of the subjective condition under which alone it can give a corresponding intuition to the concepts of understanding, belongs to sensibility; but insofar as its synthesis is still an exercise of spontaneity, which is determining and not, like sense, merely determinable, and can thus determine the form of sense a priori in accordance with the unity of apperception, the imagination is to this a faculty for determining the sensibility a priori, and its synthesis of intuitions, in accordance with the categories, must be the transcendental synthesis of the imagination, which is an effect of the understanding on sensibility ( $K r V$ B151-152).

Why is the synthesis of imagination a determinative one? Why is this synthesis provided according to the categories and, thereby, an effect of the understanding on sensibility? Why can imagination determine the form of sensibility according to the unity of apperception?

Now, in answering these questions, one cannot count on the methodology followed in the first part of the B-Deduction, in which Kant presented an analysis of the understanding in its pre-epistemic nature. ${ }^{14}$ It must deal with the domain of what is given to the synthesis of imagination, i.e., the domain of sensibility.

Kant ferrets out an accomplishment in the consideration of the nature of the pure forms of human sensibility. He considers that what is represented as 'determined' in these forms cannot be justified within the sensible domain. For a determination of the manifold cannot at all have its basis in this domain.

As Kant exemplifies, in his consideration of the pure form of time:

$[\ldots]$ inner sense $[\ldots]$ contains the mere form of intuition, but without combination of the manifold in it, and thus it does not yet contain any determinate intuition at all,

14 See Allison (1987: 06): “[...] it does not follow from an analysis of the understanding (or apperception) and the conditions of its unity that the sensible data will conform to these conditions". 
which is possible only through the consciousness of the determination of the manifold through the transcendental action of the imagination (synthetic influence of the understanding on the inner sense), which I have named the figurative synthesis $(\operatorname{KrV} \mathrm{B} 154) .{ }^{15}$

It is in this passage that Kant first provides a justification of the relation of the understanding to sensibility. He notes that the synthesis of the faculty of imagination, in its representation of the forms of human sensibility, provides the proof that the categories necessarily determine the pure intuitions of space and time. In short, pure forms of human sensibility, as a result of the synthesis of the imagination, could only be so due to a 'synthetic influence of the understanding' on sensibility.

What grounds this possibility is Kant's conception of imagination, within the B-Deduction argument, as a faculty that, in what matters to the transcendental justification of human cognition, is necessarily reliant upon the faculty of understanding. That is to say, his conception that "[i]t is one and the same spontaneity that, there under the name of imagination and here under the name of understanding, brings combination into the manifold of intuition" ( $K r V \mathrm{~B} 162$, footnote). ${ }^{16}$

The last feature of the task of relating the understanding to sensibility is the proof that categories determine also empirical intuitions. In $\S 26$, Kant attends to this feature by considering space and time as pure intuitions of human sensibility.

\footnotetext{
${ }^{15}$ In his letter to Beck from 1792, Kant explains this moment of his argumentation as follows: "I wanted then to make the Deduction of the categories comprehensible by showing its relation to the sensuous forms of space and time, as the conditions of the uniting of these for a possible experience" ( $\mathrm{Br}, \mathrm{A} 11$ : 314).

16 See Caimi (2008: 39): "[i]n the 1781 edition, imagination is presented as an independent faculty: 'There are three original sources (faculties of the soul) which contain the conditions of possibility of every experience, and cannot be derived in turn from any other faculty of the mind; i.e.; sense, imagination and apperception' (A 94). In the second edition, of 1787, imagination is assimilated to understanding, which in this sense remains as the only faculty of spontaneity. The action of imagining, in 1787, 'is an action of the understanding upon sensibility' (B 151-152). Perhaps the most well-known testimony of this shift in Kant's thought regarding imagination is the hand-written correction to his own volume of the first edition, which modifies a passage in A 78: where he had written that imagination is 'a blind function, though indispensable, of the soul', he jotted 'a function of understanding'". Caimi sustains that "[...] the identification of imagination with understanding belongs to a modern conception of imagination, which differs from the traditional conception (Aristotelian and Wolffian) that defines imagination as the faculty of representing in the intuition what is not there (i.e. in intuition)" (2008: 40) and draws the conclusion that "[i]t is the awareness of th[e] independence of sensibility which allows Kant to conjoin the Wolffian conception of imagination to the one we found in Descartes and Spinoza, which distinguishes imagination from understanding only through its object: sensibility" (2008: 49).
} 
Kant points out that, in the first part of the B-Deduction, a 'transcendental deduction' or justification ${ }^{17}$ of the categories within the domain of the understanding implied showing "[...] their possibility as $a$ priori cognitions of objects of an intuition in general" ( $K r V \mathrm{~B} 154) . \mathrm{He}$ observes, however, that, in order to accomplish the task of the deduction, "[...] the possibility of cognizing a priori through categories whatever objects may come before our senses, not as far as the form of their intuition but rather as far as the laws of their combination are concerned, [...] is to be explained" ( $K r V$ B154).

Accordingly, the accomplishment of the task of the deduction is not restricted either to the domain of the understanding (to the unity of a sensible intuition in general) or to the form of the domain of sensibility (to the representation of the manifold in space and time). Instead, it requires attending to the unity of intuition that amounts to cognition in the domain of sensibility. ${ }^{18}$

\footnotetext{
${ }^{17}$ On the equivalence of 'deduction' and 'justification', see Paton (1965: 313).

${ }^{18}$ The deduction of the categories can, therefore, be accomplished within the B-Deduction argument insofar as the concept of 'unity' approached in its first part-i.e., the unity of sensible intuition - is rendered a concept of the sensible unity of intuition. Thus, Kant's 1787 argument for the categories begins with an element that establishes what is characteristic of the understanding (the unity of sensible intuition) and culminates in an element that, within what is peculiar to the domain of sensibility (the sensible unity of intuition), ensures the legitimate use of these pure concepts of the understanding. I here disagree with Höffe, who, in his evaluation of the argument, states that "[i]t is striking that at no stage does the 'deduction' refer to any individual categories, or even to any specific classes of category, but only to categories in general, to what we might call mere categoriality itself. One might therefore think that Kant is now relativizing [relativiere] his earlier claim to completeness with regard to the table of categories" (2010: 149 - in the English version used here, the German 'relativiere' is translated as 'qualifying'). As he also puts it elsewhere: "[n]owhere in the Transcendental Deduction does Kant discuss the content of the various categories; Fichte's corresponding criticism (Second Introduction to the Science of Knowledge: 'Zweite Einleitung in die Wissenschaftslehre', 6) is correct; Kant's only goal is to demonstrate the objective validity of the categories in general" (Höffe 1994: 75-76). As I have argued, in the B-Deduction, Kant's methodological strategy for achieving the task of the deduction implies establishing the understanding as an active faculty of determination and justifying that it is the only possible ground of what is given as necessarily determined in sensibility. Moreover, he advances this strategy by presenting an element that is characteristic of the understanding and ensuring that, as to the use of its a priori concepts, this element has a correlate in sensibility. In a word, in polarizing the two parts of the deduction task, the concept of 'unity' is set as the beginning and the outcome of the categories' activity of synthesis. Consequently, it is difficult to grasp why and how specifying the categories would be an important matter in any of these two parts that are implied in the task of the deduction. Thus, it seems that what Höffe is seeking in the deduction argument should be sought at another moment of Kant's argumentation-i.e., at the one that is devoted to specifying " $[\ldots]$ the application of the pure concepts of understanding to possible experience" ( $K r V$ A160/B199) - , namely, the Analytic of Principles.
} 
Kant's proof that the categories provide the sensible unity of empirical intuitions can be broken down in the following four moments: ${ }^{19}$

[i)] We have forms of outer as well as inner sensible intuition a priori in the representations of space and time, and the synthesis of the apprehension [i.e., the composition of the manifold in an empirical intuition] of the manifold of appearance must always be in agreement with the latter, since it can only occur in accordance with this form $(K r V \mathrm{~B} 160)$.

As the passage clearly indicates, any manifold of representations in the domain of sensibility has the representations of space and time as its ground. This means that, as regards human sensibility, nothing can be represented without first counting on space and time as pure forms.

[ii)] But space and time are represented a priori not merely as forms of sensible intuition, but also as intuitions themselves (which contain a manifold), and thus with the determination of the unity of this manifold in them ( $K r V$ B160).

In this second passage, Kant emphasizes that space and time are also given in human sensibility as one space and as one time. Thus, as intuitions that contain a manifold of representations that is determined in its unity (see $K r V$ B161, footnote). ${ }^{20}$ In such a characterization, space and time are defined as formal intuitions or pure intuitions of human sensibility.

[iii)] Thus even unity of the synthesis of the manifold, outside or within us, hence also a combination with which everything that is to be represented as determined in space or time must agree, is already given a priori, along with (not in) these intuitions, as condition of the synthesis of all apprehension ( $K r V \mathrm{~B} 161)$.

\footnotetext{
${ }^{19}$ In discussing these moments, I am following the division proposed by Allison (2015: 194-195).

${ }^{20}$ Kant here notes that "[...] since through it [the synthesis of imagination] (as the understanding determines the sensibility) space or time are first given as intuitions, the unity of this a priori intuition belongs to space and time, and not to the concept of the understanding". Kant's aim, within this moment of the second part of the B-Deduction argument, is precisely the consideration of this unity, now (re)presenting what is receptivity in human sensibility, as necessarily counting upon the activity of discursivity, i.e., the conceptual apparatus of the faculty of understanding.
} 
Unlike the previous passages, Kant is here clearly concerned with what is actually given as cognition in human sensibility. He argues that this 'given' is 'represented as determined in space or time' and implies their unity. Otherwise expressed, everything that is represented according to the pure forms of intuition implies that space and time are themselves unities as intuitions. In brief, the synthesis of representations in empirical intuitions implies the unity that is characteristic of pure intuitions.

[iv)] But this synthetic unity [of apprehension] can be none other than that of the combination of the manifold of a given intuition in general in an original consciousness, in agreement with the categories, only applied to our sensible intuition $(K r V \mathrm{~B} 161)$.

In this last passage, Kant maintains that the synthesis of apprehension-i.e., the synthesis of the manifold of empirical intuitions, which is necessarily undertaken in the domain of sensibility according to the pure forms of space and time, and implies their unity as pure intuitions - can only be justified from that unity that is characteristic of the domain of the understanding. Accordingly, the synthesis of what is given in sensibility as empirical intuition and amounts to an object of cognition necessarily implies the unity of the consciousness of the subject (the principle upon which an objective determination according to the categories relies). ${ }^{21}$

With this fourth moment, Kant achieves the outcome that empirical intuitions are necessarily under the categories and, therefore, that human

\footnotetext{
${ }^{21}$ It is worth taking into account other two passages in which Kant approaches this issue: i) "Synthetic unity of apperception a priori is the synthesis of the manifold in accordance with an a priori rule. The logical function is the action of unifying the same consciousness with many representations, i.e., of thinking a rule in general. The unity of intuition a priori is only possible through the combination of the manifold in one apperception, which must therefore take place a priori, consequently also the unity of the synthesis of all empirical intuitions, since they are to be encountered in space and time" (Refl 5642, AA 18: 282); ii) "Two sorts of representations are needed for cognition: 1) intuition, by means of which an object is given, 2) concept, by means of which it is thought. To make a single cognition out of these two pieces of cognition a further activity is required: the composition of the manifold given in intuition in conformity with the synthetic unity of consciousness, which is expressed by the concept. Since composition, either through the object or through its representation in intuition, cannot be given but must be produced, it must rest on the pure spontaneity of the understanding in concepts of objects in general (of the composition of the given manifold)" (Letter to Beck, from 1792; Br, AA 11: 315$316)$.
} 
cognition is justified by means of a necessary relation between theoriginally distinct — domains of the understanding and sensibility. ${ }^{22}$

In advancing an argumentation that presents both pure and empirical intuitions under the activity of synthesis provided by the categories and, therefore, endowed with a sensible unity which is only possible due to the performance of these pure concepts of the understanding, Kant accomplishes his aim in the second part of the B-Deduction. In short, the sensible unity of intuition accounts for the relation of the understanding and sensibility.

\section{Concluding remarks}

I have argued that the B-Deduction argument can be methodologically understood as a justification of the necessity of the categories for the unity of sensible intuition - set in the understanding — and its correlate, sensible unity of intuition - presented in sensibility. This means that the argument contends with the two features implied in this justification, i.e., the distinctiveness and the necessary relation of the understanding and sensibility.

In attending to Kant's definition of 'transcendental cognition', it was observed that only in the B-Deduction argument Kant presents an approach presiding over the justification of the categories as pure concepts endowed with legitimate use. Moreover, in addressing this argument's methodology, it was noted that, while the first part of the argument revolves around an analysis of the understanding; its second part calls upon a synthetic methodology relating the understanding to sensibility. Finally, in presenting and discussing the B-Deduction argumentation, it was elucidated that its first part deals with a pre-epistemological justification of the categories' activity of synthesis (the unity of sensible intuition) and its second part is devoted to

\footnotetext{
${ }^{22}$ In a passage from the Fortschritte der Metaphysik, Kant presents a summary of this outcome in what matters to the two parts of the B-Deduction argument: "[k]nowledge is a judgment from which proceeds a concept that has objective reality, i.e., to which a corresponding object can be given in experience. But all experience consists in the intuition of an object, i.e., an immediate and individual representation, through which the object is given as to knowledge, and a concept, i.e., a mediate representation through a characteristic common to many objects, whereby it is therefore thought. Neither of the two types of representation constitutes knowledge on its own, and if there are to be synthetic a priori cognitions, there must also be a priori intuitions as well as concepts, whose possibility must therefore first be discussed, and then their objective reality proved through the necessary use of them, in virtue of the possibility of experience" (FM, AA 20: 266).
} 
explaining that and how this activity is performed in human sensibility in order to provide cognition (the sensible unity of intuition).

If the approach offered in this essay is convincing, it has important implications for the insight into Kant's theoretical philosophy and his effort in the transcendental deduction. With it, one may understand why Kant gave up an argument beginning with an analysis of human cognition as a whole and advanced an argument that starts with an analysis of the understanding's function of unity and ends with a synthetic explanation of the necessary relation of this activity to sensibility's spatiotemporal givenness. This, I suggest, is an essential methodological key for grasping what Kant was getting at in the proof-structure of the B-Deduction argument. ${ }^{23}$

\section{References}

ALLISON, H. E.: "Reflections on the B-Deduction", The Southern Journal of Philosophy 25 (1987) 1-16.

: Kant's transcendental deduction: an analytical-historical commentary, New York, Oxford University Press, 2015.

BAUMANNS, P.: Kants Philosophie der Erkenntnis: durchgehender Kommentar zu den Hauptkapiteln der "Kritik der reinen Vernunft", Würzburg, Königshausen \& Neumann, 1997.

CAIMI, M.: "Comments on the Conception of Imagination in the Critique of Pure Reason", in ROHDEN, V.; TERRA, R. R.; DE ALMEIDA G. A.; RUFFING, M. (eds.): Recht und Frieden in der Philosophie Kants - Akten des X. Internationalen Kant-Kongresses, Berlin/New York, Walter de Gruyter, 2008.

: Kant's B Deduction, Newcastle, Cambridge Scholars Publishing, 2014.

ERDMANN, B.: Beiträge zur Geschichte und Revision des Textes von Kants Kritik der reinen Vernunft, Berlin, G. Reimer, 1900.

HENRICH, D.: "The proof-structure of Kant's transcendental deduction", The Review of Metaphysics 22 (1969) 640-659.

HINSKE, N.: Kants Weg zur Transzendentalphilosophie, Berlin, Kohlhammer, 1970.

${ }^{23}$ I would like to express my gratitude to Professor Mario Caimi for his valuable comments and suggestions on an earlier version of this paper. 
HÖFFE, O.: Immanuel Kant, Albany, State University of New York Press, 1994.

: Kant's Critique of pure reason: the foundation of modern philosophy, London/New York, Springer, 2010.

KANT, I.: Lectures on logic $[V-L o g]$, trans. YOUNG, J. M., New York, Cambridge University Press, 1992.

: Critique of pure reason $[K r V]$, trans. GUYER, P., New York, Cambridge University Press, 1998.

: Correspondence $[\mathrm{Br}]$, trans. ZWEIG, A., New York, Cambridge University Press, 1999.

: Notes and fragments [Refl], trans. BOWMAN, C.; RAUSCHER, F.; GUYER, P., New York, Cambridge University Press, 1999.

: Prolegomena to any future metaphysics that will be able to come forward as science [Prol], trans. HATFIELD, G., New York, Cambridge University Press, 2002.

: What real progress has metaphysics made in Germany since the time of Leibniz and Wolff? [FM], trans. HATFIELD, G., New York, Cambridge University Press, 2002.

LONGUENESSE, B.: Kant and the capacity to judge, Princeton/Oxford, Princeton University Press, 2000.

PATON, H. J.: Kant's metaphysics of experience, New York, Macmillan, 1965. 